\title{
The glutamate system as a therapeutic target and impact of genes on suicidality
}

\author{
Andrea Schmitt • Peter Falkai
}

Published online: 2 July 2013

(c) Springer-Verlag Berlin Heidelberg 2013

Based on the fact that antagonists at the glutamatergic $\mathrm{N}$-methyl-D-aspartate (NMDA) receptor cause psychosis, a dysfunction of the glutamate system has been proposed to play a role in schizophrenia and major depression. In a detailed review, Hashimoto et al. [1] compared schizophrenia add-on treatments with glycine, D-serine, D-alanine, D-cycloserine, D-amino acid oxidase inhibitors and recently glycine transporter inhibitors as well as modulators of group II metabotropic glutamate receptors, which have shown to improve function of the NMDA receptor and exert effects on negative symptoms and cognition. In depression, an overactive glutamate system has been suggested due to magnetic resonance spectroscopy (MRS) studies reporting increased levels of glutamine/glutamate in the frontal and occipital cortex. Concordantly, NMDA receptor antagonists, partial antagonists at the glycine site of the receptor, metabotropic glutamate receptor (mGluR) $2 / 3$ and mGluR5 allosteric modulators have been proven to be effective in animal models and first clinical trials. In the need of innovative treatment approaches in major psychiatric disorders, such investigations should be encouraged and may lead to new add-on therapeutic strategies. A dysregulation of the glutamate system has been implicated in autism as well. In a MRS study at 4 Tesla measuring glutamate levels more accurately, Joshi et al. [2] compared patients suffering from autistic disorder to healthy controls. They found higher glutamate levels in the anterior cingulate cortex and a similar trend in the right medial temporal lobe in autism, indicating higher glutamate activity in these

A. Schmitt $(\bowtie) \cdot$ P. Falkai

Department of Psychiatry and Psychotherapy,

Ludwig-Maximilians-University Munich, Nußbaumstr. 7,

80336 Munich, Germany

e-mail: Andrea.Schmitt@med.uni-muenchen.de patients. Since many risk genes are targeting the glutamate system, in larger study effects of polymorphisms should be investigated.

The cytochrome $\mathrm{P} 450$ oxidase group is involved in the metabolism of antidepressants. In treatment-resistant depression, suicidality has been associated with the cytochrome P450 metabolizer status. Höfer et al. [3] investigated the impact of cytochrome P450 genes on suicide attempts and suicide risk in treatment-resistant major depression. No association has been found after corrections for multiple testing, but results should be verified in a larger sample. In contrast, Antypa et al. [4] found variations in three monoamine oxidase A (MAOA) genes to be associated with higher levels of outwardly expressed anger in male suicidal patients. They suggest MAOA genes to be related to impulsivity, anger and aggression, which are risk factors for suicidality. Recent studies reported a potential association of polymorphisms in brain-derived neurotrophic factor (BDNF) genes with worse treatment outcome in patients with melancholic depression. Musil et al. [5] genotyped three BDNF polymorphisms in 324 patients with major depression and 470 healthy controls. No associations with diagnosis have been detected, but in tendency, rs6265 was associated with treatment response. However, this investigation is a pilot study and needs replication in larger patient samples to receive more reliable results.

Since inpatients with depression tend to high relapse rates and chronicity, in a prospective study, Kuehner and Huffziger [6] identified predictors for outcome such as psychosocial functioning, depression levels at discharge and unsatisfactory relationships within the support network. The authors assume a need of treatment until full remission plus individual psychological interventions. Furthermore, affective disorders are associated with an 
increased mortality risk. In a until 2009 conducted followup study of 403 inpatients with affective disorders between 1959 and 1963 at the Psychiatric hospital of Zurich University in the last 5 decades, Angst et al. [7] show that patients with mania had the highest mortality ratio for cardiovascular deaths and the group with major depression for deaths by suicide. Interestingly, diagnosis-dependent, long-term medication had a protective effect against mortality. Psychosocial stress and socioeconomic status again seem to influence the risk of suicide. Fountoulakis et al. [9] report low suicidal rates in Greece between 2000 and 2011 and no relationship to socioeconomic environment. They suggest no increase in suicidality during the economic crisis. Nevertheless, further investigations of the years 2012-2013 are warranted. Childhood maltreatment and low socioeconomic status have detrimental effects on adult mental health and cognitive performance. In 94 healthy monocygotic twin pairs, Goldberg et al. [8] found effects of childhood maltreatment on memory to be evident in the high, but not in the low socioeconomic group. The results suggest that a rather stressful environmental enrichment may provide a more stable context and that effects of environmental enrichment on mental health should be investigated in more detail.

\section{References}

1. Hashimoto K, Malchow B, Falkai P, Schmitt A (2013) Glutamate modulators as potential therapeutic drugs in schizophrenia and affective disorders. Eur Arch Psychiatr Clin Neurosci. doi:10.10 07/s00406-013-0399-y
2. Joshi G, Biederman J, Wozniak J, Goldin RL, Crowley D, Furtak S, Lukas SE, Gönenç A (2012) Magnetic resonance spectroscopy study of the glutamatergic system in adolescent males with highfunctioning autistic disorder: a pilot study at 4T. Eur Arch Psychiatr Clin Neurosci. doi:10.1007/s00406-012-0369-9

3. Höfer P, Schosser A, Calati R, Serretti A, Massat I, Kocabas NA, Konstantinidis A, Linotte S, Mendlewicz J, Souery D, Zohar J, Juven-Wetzler A, Montgomery S, Kasper S (2012) The impact of cytochrome P450 CYP1A2, CYP2C9, CYP2C19 and CYP2D6 genes on suicide attempt and suicide risk-a European multicentre study on treatment-resistant major depressive disorder. Eur Arch Psychiatr Clin Neurosci. doi:10.1007/s00406-012-0375-y

4. Antypa N, Giegling I, Calati R, Schneider B, Hartmann AM, Friedl M, Konte B, Lia L, De Ronchi D, Serretti A, Rujescu D (2012) MAOA and MAOB polymorphisms and anger-related traits in suicidal participants and controls. Eur Arch Psychiatr Clin Neurosci. doi:10.1007/s00406-012-0378-8

5. Musil R, Zill P, Seemüller F, Bondy B, Obermeier M, Spellmann I, Bender W, Adli M, Heuser I, Zeiler J, Gaebel W, Maier W, Rietschel M, Rujescu D, Schennach R, Möller H-J, Riedel M (2012) No influence of brain-derived neurotrophic factor (BDNF) polymorphisms on treatment response in a naturalistic sample of patients with major depression. Eur Arch Psychiatr Clin Neurosci. doi:10.1007/s00406-012-0364-1

6. Kuehner C, Huffziger S (2012) Factors predicting the long-term illness course in a cohort of depressed inpatients. Eur Arch Psychiatr Clin Neurosci. doi:10.1007/s00406-012-0379-7

7. Angst J, Hengartner MP, Gamma A, von Zerssen D, Angst F (2012) Mortality of 403 patients with mood disorders 48 to 52 years after their psychiatric hospitalisation. Eur Arch Psychiatr Clin Neurosci. doi:10.1007/s00406-012-0380-1

8. Goldberg X, Alemany S, Fatjó-Vilas M, González-Ortega I, González-Pinto A, Cuesta MJ, Fañanás L (2012) Twin-based study of the complex interplay between childhood maltreatment, socioeconomic status and adult memory. Eur Arch Psychiatr Clin Neurosci. doi:10.1007/s00406-012-0382-z

9. Fountoulakis KN, Savopoulos C, Siamouli M, Zaggelidou E, Mageiria S, Iacovides A, Hatzitolios AI (2012) Trends in suicidality amid the economic crisis in Greece. Eur Arch Psychiatr Clin Neurosci. doi:10.1007/s00406-012-0385-9 